\title{
Quantification of Orlistat by a Validated, Simple and Sensitive High Performance Thin Layer Chromatographic-Densitometric Assay Method
}

\author{
Hitendra Joshi ${ }^{1{ }^{1 *},}$ Yogesh Naliyapara ${ }^{1}$, Vijay Ram ${ }^{2}$, Madhavi Patel ${ }^{1}$, Pragnesh Dave ${ }^{2, \#}$ \\ ${ }^{1}$ Department of Chemistry, Saurashtra University, Rajkot, Gujarat, India \\ ${ }^{2}$ Department of Chemistry, KSKV Kachchh University, Bhuj, Gujarat, India \\ ${ }^{\#}$ Present address: Department of Chemistry, Sardar Patel University, Vallabh Vidyanagar (Gujarat), India \\ *Corresponding Author: Hitendra Joshi, Department of Chemistry, Saurashtra University, Rajkot, \\ Gujarat, India
}

\begin{abstract}
The Objective of the current study was quantification of orlistat by a validated, simple and sensitive high performance thin layer chromatographic-densitometric assay method. Separation of Orlistat was carried out on silica gel 60F254, $10 \times 10 \mathrm{~cm}^{2}$ thin layer chromatography (TLC) plates with $6 \mathrm{~mm}$ band length and $10 \mu \mathrm{l}$ injection volume. Development chamber was saturated for $30 \mathrm{~min}$. prior. Ascending chromatography TLC plate developed using mobile phase containing $n$-hexane, ethyl acetate, glacial acetic acid $(7: 3: 0.1 \mathrm{v} / \mathrm{v} / \mathrm{v})$ respectively in glass twin-trough development chamber. The plates were developed up to a distance of $80 \mathrm{~mm}$ at temperature of $25^{\circ} \mathrm{C}$ and dried with hair drier at $50^{\circ} \mathrm{C}$. Quantification was carried out with CAMAG TLC Scanner 3 operated by WinCats software using a deuterium lamp. The linear regression equation for Orlistat was $y=847.15 x+3557.3$ with correlation co-efficient 0.9984. The LOD value for Orlistat was found to be $1.14 \mu \mathrm{g} / \mathrm{ml}$, and the $L O Q$ value $3.81 \mu \mathrm{g} / \mathrm{ml}$. The mean recovery for Orlistat was 99.13-99.92\%. The \%RSD values for intermediate and method precision study was $0.017 \%$ and mean \% assay was $99.79 \%$ as well as absolute difference between mean \% assay values of method precision and intermediate precision found $0.04 \%$ for Orlitat. The effects of such deliberate changes on peak area and \% assay were calculated, which found $99.60 \%$ to $100.12 \%$ as well as \% RSD for retardation factor found $0.67 \%$. There was no indication of compound instability in the sample solution was found through the study.
\end{abstract}

Keywords: orlistat; high performance thin layer chromatographic; densitometric assay method; LOD value; Method validation; Assay Method

\section{INTRODUCTION}

Obesity is medical condition of human in which execs body fat store in body to extant that it may pose bad effect on human health [1]. Person with Body mass index which is the ratio of person's weight to the square of his/her height, is over $30 \mathrm{~kg} / \mathrm{m}^{2}$ is considered obese generally people with body mass index between $25-30 \mathrm{~kg} / \mathrm{m}^{2}$ defined as overweight [1]. Obesity in human increases the tendency of various diseases especially heart decease, diabetes type 2, obstructive sleep apnea, certain class of cancer, and osteoarthritis.[2]

Obesity is combination of excessive food in regular intake, no any physical activity and genetic susceptibility [1][3].some cases observed due to the mental illness, genes, endocrine disorders [4]. Obese people require more energy to maintain increased body mass as compare to other peoples. [5][6]

Obesity must be preventable through social change and personal choice. [1] Change in regular diet and exercise is main treatment for obesity. [2] Reducing high sugar and fat containing food, and increasing intake of fiber in regular diet, quality of diet can increases.[1]combination of medicinal treatment and suitable diet is also taken to reduce appetite or decrease fat absorption.[7]

\section{ORListat}

Orlistat is drug which is used for the treatment of obesity and it sold in market as a prescription drug with tread name Xenical by in most of nations, also sold in UK with name alli by GlaxoSmithKline. It act as lipase inhibitor and prevents reducing of fate from human diet thus calorie intake is reduces [8]. 


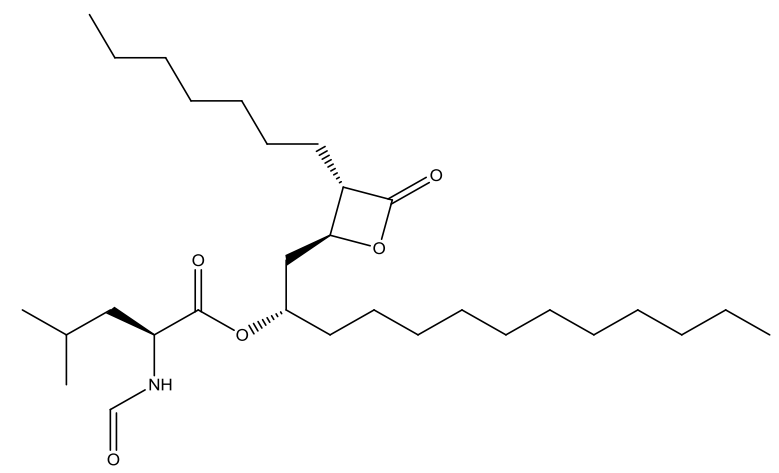

Figure1. Chemical structure of Orlistat

Orlistat is derivative of lipstatin with high potency of pancreatic lipases which is isolated from bacterium Streptomycestoxytricini [9]. Due to its simplicity and stability from others lipstatin, it was chosen as an anti obesity drug. [10]

Orlistat is useful for the various treatments such as weight loss [11] and as a secondary effect it reduces the blood pressure. Its preventive effect for the type 2 diabetes is also reported [12].

Each drug has positive and negative effects too. Orlistat is notorious due to its gastrointestinal side effect which can include steatorrhea, which are decreases with time and reported as adverse effect of drug. [12]

\section{LITERATURE REVIEW}

The literature reviews regarding Orlistat suggested that various analytical methods are reported for stability of Orlistat in pharmaceutical formulations and in various biological fluids by using various analytical techniques as UV, HPLC, UPLC, and TLC method. The literature reviews regarding these methods are as under.

\section{EXPERIMENTAL}

\subsection{Chemicals and Reagents}

An active pharmaceutical ingredient (API) working standard of Orlistat was gifted by Dr. Y. T. Naliapara, Assistant Professor, Department of Chemistry, Saurashtra University, Rajkot.

HPLC grade Dichloro methane (MDC), ethyl acetate, glacial acetic acid and n-hexane were procured from Merck India Limited, Mumbai, India. High purity deionised water was prepared using Milli-Q (Millipore, Milford, MA, USA) water purification system. Nylon syringe filters $0.22 \mu \mathrm{m}$ were from Millex-Hn (Mumbai, India). TLC plates used were obtained from Merck India Limited, Mumbai, India.

\subsection{Instrumentation}

CAMAG HPTLC system used for quantitative analysis consisted of $100 \mu 1$ sample syringe (Hamilton, Switzerland), CAMAG Linomat V applicator (Camag, Switzerland), CAMAG glass twin-trough chambers $\left(20 \times 10 \times 4 \mathrm{~cm}^{3}\right)$; TLC plate visualizing chamber and CAMAG TLC scanner III. Chromatographic data Equalization and instrument control were done using WinCATS software (V 1.4.2, CAMAG). The source of radiation was a deuterium lamp emitting a continuous UV spectrum in the range $190-400 \mathrm{~nm}$.

\subsection{Mobile Phase Preparation}

The mobile phase was made of, $\mathrm{n}$-hexane, ethyl acetate, glacial acetic acid (7:3:0.1 v/v/v)

\subsection{Diluents Preparation}

Dichloro methane used asdiluents.

\subsection{Standard Preparation}

Standard stock solution containing Orlistat $2000 \mu \mathrm{g} / \mathrm{mlwas}$ prepared by taking $20.0 \mathrm{mg}$ Orlistat in 10 $\mathrm{ml}$ volumetric flask, $5 \mathrm{ml}$ of diluents (methylene dichloride) was added, sonicated and cooled to room 
temperature. The solution was diluted to the mark with diluents. Standard solution containing Orlistat $(200 \mu \mathrm{g} / \mathrm{ml})$ was prepared by pipetting $1 \mathrm{ml}$ stock solution into a $10 \mathrm{ml}$ volumetric flask and diluted up to the mark with diluents.

\subsection{Chromatographic Conditions}

Separation of Orlistat was carried out on silica gel $60 \mathrm{~F} 254,10 \times 10 \mathrm{~cm}^{2}$ thin layer chromatography (TLC) plates with $6 \mathrm{~mm}$ band length and $10 \mu \mathrm{l}$ injection volume. Development chamber was saturated for 30 min. prior. Ascending chromatography TLC plate developed using mobile phase containing nhexane, ethyl acetate, glacial acetic acid (7:3:0.1 v/v/v) respectively in glass twin-trough development chamber. The plates were developed up to a distance of $80 \mathrm{~mm}$ at temperature of $25^{\circ} \mathrm{C}$ and dried with hair drier at $50^{\circ} \mathrm{C}$. Quantification was carried out with CAMAG TLC Scanner 3 operated by WinCats software using a deuterium lamp.

\section{RESULTS AND DISCUSSION}

\subsection{Development and Optimization of the HPTLC Method}

An analytical method based on TLC using densitometric detection was developed and validated for assay determination of Orlistat API. The analytical conditions were selected, keeping in mind the different chemical nature of Orlistat. The chemical and physical parameters e.g. solubility, pH, polar or nonpolar nature of the compound and peak wavelength. According to the literature review, the $\lambda$ $\max$ values of were reported 190-220 $\mathrm{nm}$. For the multi-component analysis of the drugs, most suitable wavelength was chosen; considering the maximum response were observed at $208 \mathrm{~nm}$.

The mobile phase selection has been done on the basis of resolution, Symmetry of peak, spot definition sensitivity and day-to-day reproducibility of the retardation factor and intensity or peak height and peak area Orlistat peaks. After evaluating all these factors, Nonpolar and polar solvent mixture was found to be giving satisfactory results. Initial trial was taken using methanol and chloroform as a mobile phase but we didn't get good peak shape (Trial 1, fig.2).

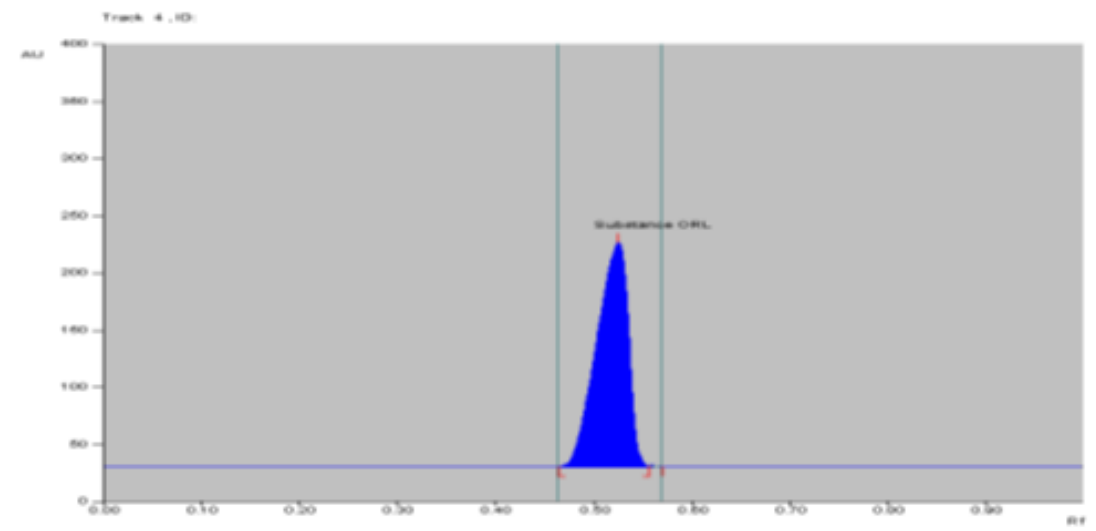

Figure2. Chromatogram of method development (Trial 1)

When chloroform was replaced by ethyl acetate the peak shape and little separationof drug was improved. (Trial 2, fig.3)

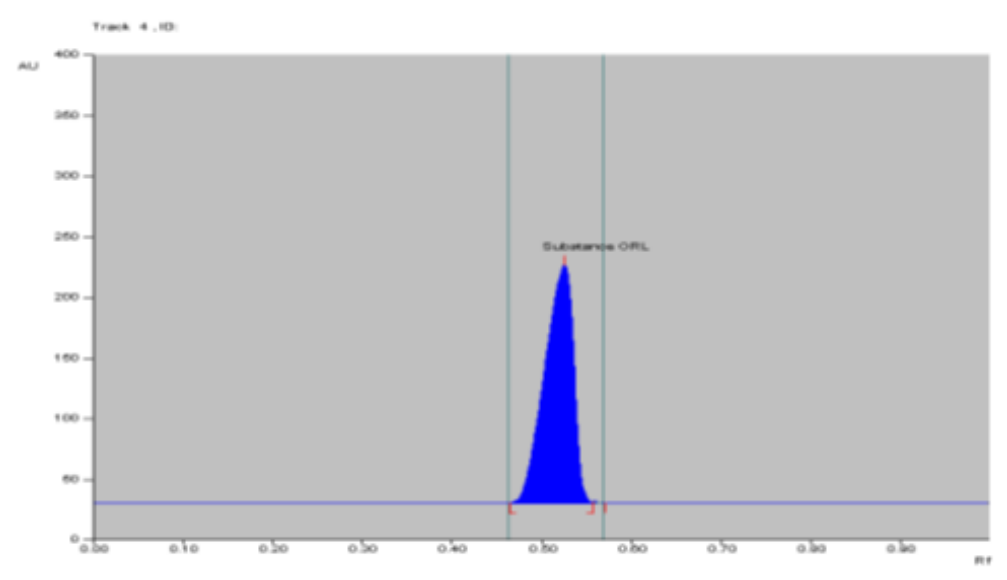

Figure3. Chromatogram of method development (Trial 2) 
After so many trial of method optimization, Orlistat was found suitable for faster development, resolution and peak shape of both components. Finally, the mobile phase composition consisted of a mixture of Hexane: Ethyl acetate: Glacial acetic acid (7.0:3.0:0.1 v/v/v). Optimized mobile phase proportion was providing good resolution between Orlistat. For the selection of polar organic constituent of mobile phase, Ethyl acetate was chosen to increase the retardation factor and to attain good peak shape with resolution. Figure (4 and 5) represents the chromatograms of standard and test preparation, respectively. The final optimized chromatographic conditions are given in the Table 1.

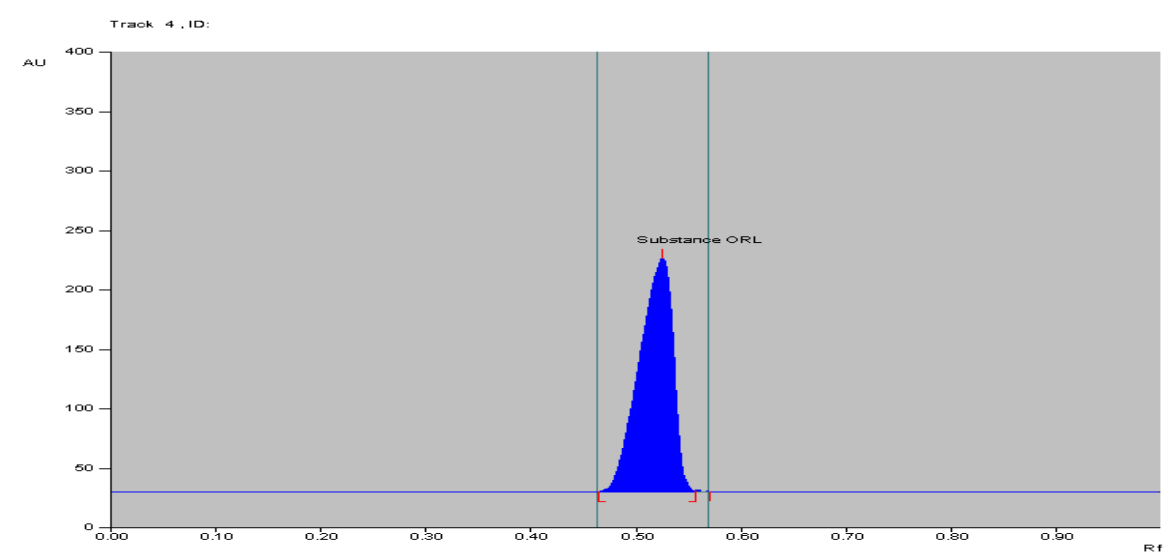

Figure4. Chromatogram of Orlistat standard preparation

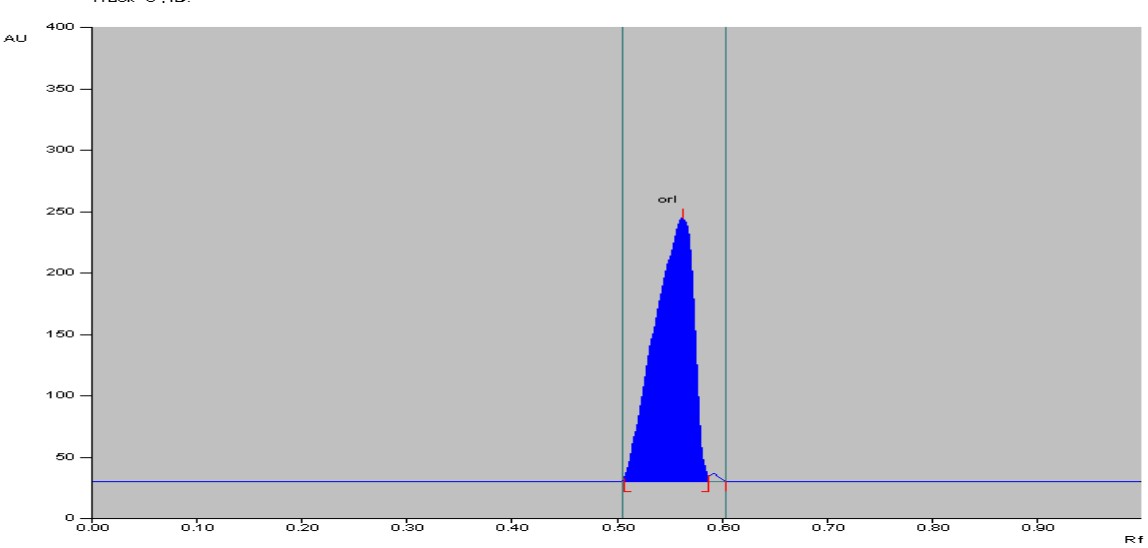

Figure5. Chromatogram of Orlistat test preparation

Table1. Optimized chromatographic conditions for HPTLC

\begin{tabular}{|c|c|}
\hline Parameters & Chromatographic Conditions \\
\hline Stationary phase & Silica gel GF254 pre-coated (aluminum sheet) \\
\hline Diluents & Dichloro methane \\
\hline Sample con.(ng/band) & 2000 (ng/band) Orlistat \\
\hline Sample applicator & CAMAG Linomate V \\
\hline Sample application speed & $100 \mathrm{nl} / \mathrm{sec}$ \\
\hline Volume & $10 \mu 1$ \\
\hline Band & $6 \mathrm{~mm}$ \\
\hline Development chamber & CAMAG Twin Trough Chamber \\
\hline Method development & Hexane: Ethyl acetate: Glacial acetic acid (7:3:0.1v/v/v) \\
\hline Chamber saturation & 30 minutes \\
\hline Development distance & 80 mm \\
\hline Drying of plate & Hair Drier \\
\hline Visualization & CAMAG UV Visualizing Chamber \\
\hline Densitometric scanner & CAMAG TLC Scanner III \\
\hline Scanning speed & $20 \mathrm{~mm} / \mathrm{sec}$ \\
\hline Detector & Deuterium Lamp \\
\hline Wavelength & $208 \mathrm{~nm}$ \\
\hline Retardation Factor & $0.54 \mathrm{~min}$ \\
\hline
\end{tabular}




\subsection{Method Validation}

\subsubsection{Solution Stability}

Solution stability test was carried out by using sample and standard preparation stored at room temperature for $48 \mathrm{~h}$. Sample and standard were stored without protection of light. The responses for the old solution were evaluated by comparison with freshly prepared standard solutions at the interval of $0 \mathrm{~h}, 12 \mathrm{~h}, 36 \mathrm{~h}$, and $48 \mathrm{~h}$. For the duration of the study of the stability of stored solutions assay was determined. At each interval solutions were applied on the plates; after development of plates, the chromatographs were evaluated for extra spots. There was no indication of compound instability in the sample solution was found through the study. Assay values acquired after $24 \mathrm{~h}$ and $36 \mathrm{~h}$ were statistically alike with the first value without measurable loss for Orlistat, respectively. Table 2 shows the summary of solution stability study.

Table2. Summary of solution stability study of Orlistat

\begin{tabular}{|c|c|c|c|}
\hline & \multicolumn{3}{|c|}{ Orlistat } \\
\hline Duration & Mean area of Standard & Mean area of test & \%Assay \\
\hline Initial & 20481.8 & 20461.3 & 99.70 \\
\hline $12 \mathrm{~h}$ & 20479.3 & 20456.5 & 100.18 \\
\hline $24 \mathrm{~h}$ & 20477.5 & 20426.3 & 99.95 \\
\hline $36 \mathrm{~h}$ & 20482.1 & 20139.9 & 98.13 \\
\hline $48 \mathrm{~h}$ & 20475.4 & 19936.9 & 97.17 \\
\hline
\end{tabular}

\subsubsection{Specificity}

Specificity is the measurement of the degree of interference from Impurity that may be expected to be present in the sample. Typically these might include impurities, degradation products, and diluents. The peak purity of bands for Orlistat in the sample was confirmed by comparing the $R_{\mathrm{f}}$ values and spectra of the bands with standards. (Figure 6) It was assessed by comparing spectra at different levels, e. g. peak- start (S), peak- max (M) and peak-end (E) position of spots. There was no interference of any peakfromthese extraneous materials.

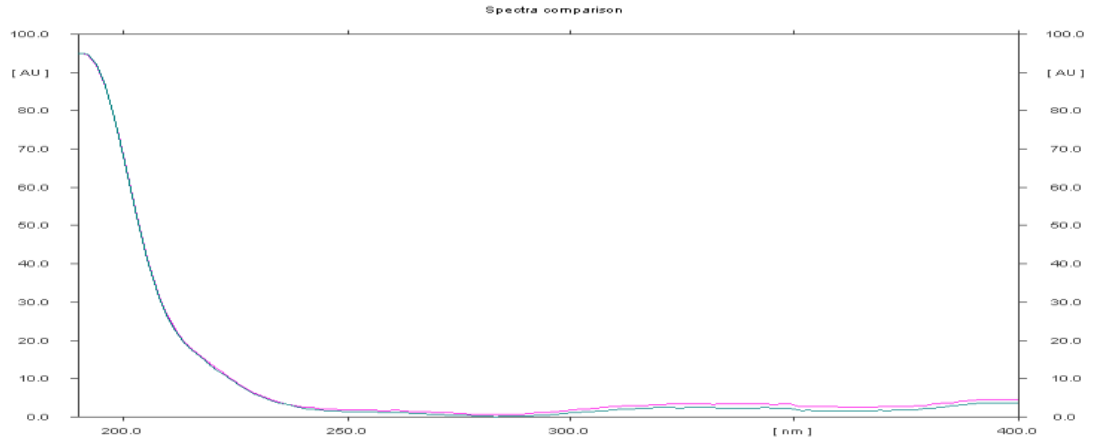

Figure6. Overlay UV spectra of Orlistat, standard and sample

\subsubsection{Linearity}

In a chromatographic method, linearity study was carried out preparing seven point calibration curve of concentration range from 80-320 $\mu \mathrm{g} / \mathrm{band}$ (800-3200 ng/band) for Orlistat. The linearity assessed by test results which are directly proportional to the concentration of analyte which are present in the sample. (Table 3) The linear regression equation for Orlistat was $y=847.15 x+3557.3$ with correlation co-efficient 0.9984 Where $\mathrm{x}$ is the concentration in $\mu \mathrm{g} / \mathrm{ml}$ and $\mathrm{y}$ is the peak area in absorbance unit. The overlay chromatogram of all the levels of linearity is given in the figure 7

Table3. Summary of concentration and linearity evaluation for Orlistat

\begin{tabular}{|c|c|c|c|c|}
\hline \multicolumn{2}{|c|}{ Linearity } & \multicolumn{3}{|c|}{ Orlistat } \\
\hline Level & \% of Level & $\begin{array}{c}\text { Con. } \\
(\boldsymbol{\mu g} / \mathbf{m l})\end{array}$ & $\begin{array}{c}\text { Con. } \\
(\mathbf{n g} / \mathbf{b a n d})\end{array}$ & $\begin{array}{c}\text { Mean } \\
\text { Area }\end{array}$ \\
\hline $\mathbf{1}$ & 40 & 80 & 800 & 10083.50 \\
\hline $\mathbf{2}$ & 60 & 120 & 1200 & 14066.70 \\
\hline $\mathbf{3}$ & 80 & 160 & 1600 & 17358.30 \\
\hline
\end{tabular}


Quantification of Orlistat by a Validated, Simple and Sensitive High Performance Thin Layer Chromatographic-Densitometric Assay Method

\begin{tabular}{|c|c|c|c|c|}
\hline 4 & 100 & 200 & 2000 & 20481.80 \\
\hline 5 & 120 & 240 & 2400 & 24363.00 \\
\hline 6 & 140 & 280 & 2800 & 27797.80 \\
\hline 7 & 160 & 320 & 3200 & 30537.90 \\
\hline \multicolumn{3}{|c|}{ Correlation Co-efficient } & \multicolumn{2}{|c|}{0.9984} \\
\hline \multicolumn{3}{|c|}{ Slope } & \multicolumn{2}{|c|}{847.15} \\
\hline \multicolumn{3}{|c|}{ Intercept } & \multicolumn{2}{|c|}{3557.3} \\
\hline
\end{tabular}

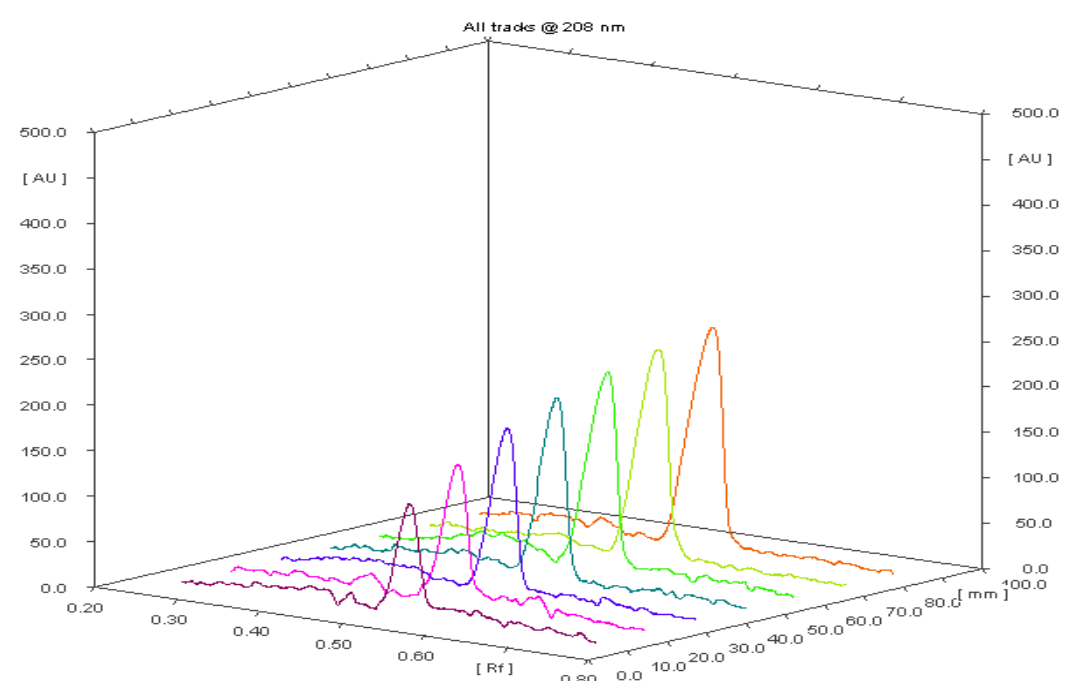

Figure7. Overlay chromatograph of seven level calibration curve

\subsection{4. $L O D$ and $L O Q$}

The limit of detection and limit of quantification were calculated using $3 \sigma / \mathrm{S}$ and $10 \sigma / \mathrm{S}$ equation for the developed method for LOD and LOQ, respectively. Where $\sigma$ is the standard deviation of the $y-$ intercept and $\mathrm{S}$ is the slope of the calibration curve. For the LOD and LOQ study, concentrations were selected in the range of 800-3200 ng/band for Orlistat, respectively. The LOD value for Orlistat was found to be $1.14 \mu \mathrm{g} / \mathrm{ml}$, and the LOQ value $3.81 \mu \mathrm{g} / \mathrm{ml}$. The result shows the sensitivity of the methods

\subsubsection{Accuracy}

The accuracy study of an analytical procedure states the degree of closeness of agreement between the conventional true value or accepted reference value and the practically found value. Recovery of an ingredients was determined at three different concentration levels. The mean recovery for Orlistat was 99.13-99.92\% .The satisfactory results indicating that the method was accurate and \% recovery found within acceptance criteria.

\subsubsection{Precision}

The precision of the method, as repeatability was evaluated by performing six independent assays of the test sample preparation and calculating the SD, \% RSD and mean \% assay. The intermediate (inter-day) precision of the method was assessed by performing same procedure on different days by other analyst under the same experimental conditions with different make chemicals. The results obtain from the repeatability study was consider for the intra-day precision study also. The \%RSD values for intermediate and method precision study was $0.017 \%$ and mean $\%$ assay was $99.79 \%$ as well as absolute difference between mean $\%$ assay values of method precision and intermediate precision found $0.04 \%$ for Orlitat.

\subsubsection{Robustness}

The robustness study was evaluated with respect to the minute but a deliberate alteration in the chromatographic conditions, the result of the study delivers the reliability of the analysis. The change in Chromatographic parameters, e.g. composition of mobile phase, volume of mobile phase, chamber saturation time, detection wavelength. The effects of such deliberate changes on peak area and \% assay were calculated, which found $99.60 \%$ to $100.12 \%$. as well as \% RSD for retardation factor found $0.67 \%$. 
Quantification of Orlistat by a Validated, Simple and Sensitive High Performance Thin Layer Chromatographic-Densitometric Assay Method

\subsubsection{System Suitability Study}

Before measurement of validation parameter a system suitability test was performed by measurement of very important characteristics such as \% RSD of peak area, \% RSD of retardation factor observed and calculated for standard solutions. (Table 4)

Table4. Summary of system suitability data of Orlistat

\begin{tabular}{|l|c|c|}
\hline $\begin{array}{l}\text { System Suitability Parameter } \\
\text { In-house Limits }\end{array}$ & $\begin{array}{c}\text { \% RSD } \text { of Area } \\
\mathbf{N M T}^{\mathbf{b}} \mathbf{2 . 0}\end{array}$ & $\begin{array}{c}\text { \% } \mathbf{R S D}^{\mathbf{a}} \mathbf{o f ~ R f}^{\mathbf{c}} \\
\mathbf{N M T}^{\mathbf{b}} \mathbf{2 . 0}\end{array}$ \\
\hline Validation Parameter & \multicolumn{2}{|c|}{ Orlistat } \\
\hline Solution Stability & 1.160 & 0.83 \\
\hline Specificity & 0.057 & 0.62 \\
\hline Linearity & 0.094 & 1.24 \\
\hline Method Precision & 0.023 & 0.78 \\
\hline Intermediate Precision & 0.150 & 1.16 \\
\hline Accuracy & 0.008 & 1.15 \\
\hline Robustness & 0.160 & 0.67 \\
\hline
\end{tabular}

The experimental results obtained and calculated are suitable for the chromatographic method with inhouse limits.

\section{CONCLUSION}

A new analytical method was developed to be routinely applied to quantification of orlistat by a validated, simple and sensitive high performance thin layer chromatographic-densitometric assay method. Orlistat act as lipase inhibitor and prevents reducing of fate from human diet thus calorie intake is reduces. In this study, an analytical method based on TLC using densitometric detection was developed and validated for assay determination of Orlistat API. The developed procedure was evaluated for System suitability study, linearity, accuracy, precision, Robustness, LOD and LOQ. Hence, the method is recommended for routine quality control analysis of assay determination of Orlistat API.

\section{ACKNOWLEDGEMENTS}

The authors are thankful for facilities and grants given under UGC - Special Assistance programmed (SAP-I) Department Research support (DRS) (Sanction letter No. 540/DRS/2004 Dt. 26/03/2004) and Department of Science and Technology New Delhi Fund for Improvement of Science and Technology (FIST) (Section letter No. SR/FST/CSI-072/2003 Dt.24/12/2003), Department of Chemistry, Saurashtra University, Rajkot 360005 (India) and Department of Chemistry, KSKV Kachchh University, Bhuj - 370 001(INDIA) for providing analytical facilities.

\section{REFERENCES}

[1] "Obesity and overweight Fact sheet N³11". WHO. January 2015. Retrieved 2 February 2016.

[2] Haslam DW, James WP (2005). "Obesity". Lancet (Review) 366 (9492): 1197-209. Doi: 10.1016/S01406736(05)67483-1.

[3] Yazdi, FT; Clee, SM; Meyre, D (2015). "Obesity genetics in mouse and human: back and forth, and back again.” PeerJ 3: e856. Doi:10.7717/peerj.856.

[4] Bleich S, Cutler D, Murray C, Adams A (2008). "Why is the developed world obese?" Annu Rev Public Health (Research Support) 29: 273-95.

[5] Oxford Handbook of Medical Sciences ( $2^{\text {nd }}$ ed.). Oxford: OUP Oxford. 2011. p. 180. ISBN 97801916 52295.

[6] Kushner, Robert (2007). Treatment of the Obese Patient (Contemporary Endocrinology). Totowa, NJ: Humana Press. p. 158. ISBN 1-59745-400-1. Retrieved April 5, 2009.

[7] Yanovski SZ, Yanovski JA (Jan 1, 2014). "Long-term drug treatment for obesity: a systematic and clinical review." JAMA: The Journal of the American Medical Association (Review) 311 (1): 74-86. Doi: 10.1001/jama.2013.281361.

[8] Yanovski SZ, Yanovski JA (Jan 1, 2014). "Long-term drug treatment for obesity: a systematic and clinical review." JAMA: the Journal of the American Medical Association (Review) 311 (1): 74-86. Doi: 10.1001/jama.2013.281361. 
Quantification of Orlistat by a Validated, Simple and Sensitive High Performance Thin Layer Chromatographic-Densitometric Assay Method

[9] Barbier P, Schneider F (1987). "Syntheses of tetrahydrolipstatin and absolute configuration of tetrahydrolipstatin and lipstatin". Helvetica Chimica Acta 70 (1): 196-202. Doi:10.1002/hlca.1987 0700124.

[10] Pommier A, Pons M, Kocienski P (1995). "The first total synthesis of (-)-lipstatin". Journal of Organic Chemistry60 (22): 7334-7339. doi:10.1021/jo00127a045

[11] Padwal R, Li SK, Lau DC (2004). Padwal, Raj S, ed. "Long-term pharmacotherapy for obesity and overweight". Cochrane Database System Rev (3): CD004094. Doi: 10.1002/14651858.CD004094.pub2.

[12] Torgerson J, Hauptman J, Boldrin M, Sjöström L (2004). "XENical in the prevention of diabetes in obese subjects (XENDOS) study: a randomized study of orlistat as an adjunct to lifestyle changes for the prevention of type 2 diabetes in obese patients". Diabetes Care 27 (1): 155-61. Doi:10.2337/diacare. 27.1.155.

[13] Gaddam, Priyanka; Dhanalakshmi, K.; Reddy, G. Nagarjuna; Sreenivasa, S, "Differential derivative method development and validation of Orlistat by UV: a spectrophotometric technique", Journal of Advanced Pharmacy Education \& Research (2013), 3(3), 234-237.

[14] Hammadi, Reham; Almardini, M. Amer. "A fully validated HPLC-UV method for quantitative and qualitative determination of six adulterant drugs in natural slimming dietary supplements", International Journal of Pharmaceutical Sciences Review and Research (2014), 29(1), 171-174, 4 pp.

[15] Zhu, Mei-rong; Xu, Yong-huang; Wang, De-gang, "Determination of lipstatin concentration in fermentation broth with Orlistat as internal standard by RP-HPLC", Jinri Yaoxue (2013), 23(11), 720-722.

[16] Fredriksson, Robert, "HPLC method for preparing high purity Orlistat", PCT Int. Appl. (2014), WO 2014060445 A1 20140424,

[17] Xu, Yonghuang; Peng, Wei; Tang, Binxi; Wang, Degang; Liu, Defu, "Purification of Orlistat by preparative HPLC and its determination by UPLC", Zhongguo Yiyao Gongye Zazhi (2012), 43(8), 690692.

[18] Schneider, Alex; Wessjohann, Ludger A.; Severi, Juliana A.; Wagner, Vilegas, "Comparison of impurity profiles of Lip block vs. Orlistat using HPLC and LC-MS/MS", Latin American Journal of Pharmacy (2012), 31(1), 91-96.

[19] Nama, Sreekanth; Babu Rao, Chandu; Khagga, Mukkanti, "A new RP-HPLC method development and validation of Orlistat in bulk and pharmaceutical dosage forms", International Journal of Pharma Sciences and Research (2010), 1(6), 251-257.

[20] Schneider, A.; Wessjohann, L. A., "Comparison of impurity profiles of Orlistat pharmaceutical products using HPLC tandem mass spectrometry", Journal of Pharmaceutical and Biomedical Analysis (2010), 53(3), 767-772.

[21] Che, Baoquan; Zhang, Zhe; Huang, Xiaojun; Guo, Hongzhu; Wang, Zhibin, "HPLC-MS/MS identification of antiobesities in traditional Chinese medicine and health foods", Yaowu Fenxi Zazhi (2009), 29(4), 633635.

[22] Souri, Effat; Jalalizadeh, Hassan; Kebriaee-Zadeh, Abbas; Zadehvakili, Bettina, "HPLC analysis of Orlistat and its application to drug quality control studies", Chemical \& Pharmaceutical Bulletin (2007), 55(2), 251-254.

[23] Kim, Jung Yeon; Park, Hyoung Joon; Kim, Ji Won; Lee, Ji Hyun; Heo, Seok; Yoon, Chang-Yong; Cho, Sooyeul, "Development and validation of UPLC and LC-MS/MS methods for the simultaneous determination of anti-obesity drugs in foods and dietary supplements", Archives of Pharmacal Research (2016), 39(1), 103-114.

[24] Zhang, Ting-ting; Ma, Chen, "Related substances in Orlistat detected with UPLC-MS/MS", Yaoxue Xuebao (2014), 49(3), 380-384.

[25] Takahashi, Kazunaga; Hasegawa, Takashi; Ashizawa, Eiichi; Ogura, Makoto; Takahashi, Kazunaga; Saijo, Masaaki; Motoki, Yuji, "Screening analysis of pharmaceutical agents in dietary supplements using UPLC/PDA", Chiba-ken Eisei Kenkyusho Nenpo (2012), 59, 79-83.

[26] Xu, Yonghuang; Peng, Wei; Tang, Binxi; Wang, Degang; Liu, Defu; Zhu, Meirong, "Application of UPLC in Orlistat purification process", Xibei Yaoxue Zazhi (2012), 27(6), 533-535.

[27] Xu Yo nghuang; Peng, Wei; Tang, Binxi; Wang, Degang; Liu, Defu; "Purification of Orlistat by preparative HPLC and its determination by UPLC", Zhongguo Yiyao Gongye Zazhi (2012), 43(8), 690692.

[28] Zhang Ting-Ting; Ma Chen, "Related substances in Orlistat detected with UPLC-MS/MS", Yao xue xue bao; Acta pharmaceutical Sinica (2014), 49(3), 380-384. 
Quantification of Orlistat by a Validated, Simple and Sensitive High Performance Thin Layer Chromatographic-Densitometric Assay Method

[29] Tang, Jihe; Zhou, Jinge; Tang, Qingjiu; Wu, Tao; Cheng, Zhihong, “A new TLC bio-autographic assay for qualitative and quantitative estimation of lipase inhibitors", Phyto-chemical Analysis (2016), 27(1), 5-12.

[30] Tang Jihe; Zhou Jinge; Wu Tao; Tang Qingjiu; Cheng Zhihong, “A new TLC bio-autographic assay for qualitative and quantitative estimation of lipase inhibitors", Phyto-chemical analysis : PCA (2016), 27(1), $5-12$.

Citation: H. Joshi et al., "Quantification of Orlistat by a Validated, Simple and Sensitive High Performance Thin Layer Chromatographic-Densitometric Assay Method", International Journal of Advanced Research in Chemical Science (IJARCS), vol. 4, no. 11, pp. 23-31, 2017. http://dx.doi.org/10.20431/2349-0403.0411004

Copyright: (C) 2017 Authors. This is an open-access article distributed under the terms of the Creative Commons Attribution License, which permits unrestricted use, distribution, and reproduction in any medium, provided the original author and source are credited. 